\title{
Healer-driven ethnoveterinary knowledge diffusion among semi-nomadic pastoralists in Karamoja, Uganda
}

\author{
Jeanne Gradé (1, 2), Robert Weladji (3), John Tabuti (4), \\ Patrick Van Damme (1) \\ (I) Department of Plant Production, Ghent University, Belgium \\ (2) KACHEP, Moroto, Uganda \\ (3) Department of Biology, Concordia University, Montréal, Canada \\ (4) Institute of Environment and Natural Resources, Makerere University, \\ Kampala, Uganda
}

\begin{abstract}
Karamojong, semi-nomadic pastoralists of Uganda, rely on indigenous knowledge (IK) for their own healthcare and their livestock's. It is important to preserve, promote and protect $\mathrm{IK}$, in order to keep it from disappearing. One way is to facilitate its diffusion. The aim of this study was to compare the status of ethnoveterinary knowledge (EVK) in three unrelated communities to investigate whether organised healer-promoted EVK is more easily diffused and to what extent. This study applies a 'knowledge, attitude and practices' (KAP) survey to measure EVK application relating to twelve livestock diseases and sixteen remedies in different communities. Only in the community of Nabilatuk do registered healers regularly meet for participatory EVK sharing and afterwards pass on ideas to neighbours. Participants from the Lorengedwat community rarely interact with Nabilatuk while the interviewees of the Kaabong group have had virtually no chance to interact with the two other communities. In total 180 people ( 60 per site) were interviewed. Data were analysed in relation to distance from the healers' association; this significantly influenced EVK scores. Overall Nabilatuk scores were higher than those obtained in both other villages, while Lorengedwat was higher than the most distant and remote community of Kaabong. This indicates that organised healers have been effective in divulging their information and in promoting EVK diffusion.

Key words: ethnoveterinary knowledge, indigenous knowledge, knowledge diffusion, Karamoja
\end{abstract}

\section{Introduction}

The absence of adequate allopathic conventional health care systems forces remote communities throughout the world to rely on traditional medicines for their primary health care (WHO, 2002) and veterinary care (Martin et al., 200I; Schillhorn van Veen, I997). Indeed, the more isolated the community, the more its people will rely on traditional or indigenous knowledge (IK) (Vandebroek et al., 2004a). Transmission of IK can be conveyed vertically through family members, horizontally by exchange through peers, 
or diagonally through traditional healers $(\mathrm{TH})$ to student learners (Ladio \& Lozada, 200I; Philander et al., 2008). However, there is a danger that this knowledge will soon be lost as traditional social patterns are increasingly disturbed by globalisation (Somnasang and Moreno-Black, 2000). If people stop actively using IK or reduce its transmission, it falls into disuse, or becomes adulterated with mixtures of other knowledge systems (GomezBeloz, 2002; Stangeland et al., 2008).

The Karamojong provide a specific example. These semi-nomadic pastoralists found in isolated northeastern Uganda, rely chiefly on IK for addressing their health problems and maintaining their prized livestock (Gradé et al., 2007). There have been efforts to introduce conventional western medicine practices with varying success, as the latter are hardly sustainable. Most educated people have advocated discouraging local medicine practices in order to increase the use of and dependency on pharmaceuticals and modern methods, arguing that Karamoja is backwards (Muhereza \& Otim, 2002). Furthermore, there have been efforts to dissuade pastoralists from their traditional lifestyle, urging them to endorse a more settled and less bovi-centric way of life (Dyson-Hudson et al., 1998; Mandani, 1986; Quam, 1978). This has been brought about by rising investment in government and non-governmental infrastructure, social services and schools in the region, even though these exogenous development actions are still below par when compared to the rest of Uganda (Uganda Bureau of Statistics, 2002). These actions adversely affect Karamoja's IK.

Traditionally, the Karamojong identify three sources of their indigenous knowledge: Creator-God, people (both living and dead), and animal observation (Gradé et al., 2009a). Historically, they have actively shared IK within their extended family by word of mouth, repetitive visual, oral and hands-on activities, and retelling stories that constitute traditional Karamojong participatory learning methods. This transmission has waned as children increasingly attend the formal school system. There, they are influenced by teachers, a school system, and by non-kin that drive them to adopt a different, 'more modern' lifestyle, no longer linked to cattle keeping. It is through these seemingly wellmeaning interactions, that occur many times in a boarding school environment, that the youth disassociate themselves from their ancestral IK systems. This unintended consequence further discourages elders from interacting with 'perceived' stubborn and disinterested youth. In this way, schools, by their very nature, occupy much of the time that was once available for pastoral cultures to engage in IK transmission (Srithi et al., 2009; Voeks \& Leony, 2004). Therefore the youth, exposed to formal schooling, have insufficient time and minimal desire (or sense of duty) for instruction in traditional livestock care from their elders. Karamoja's IK has not only been adulterated and mixed but it also has the problem of reduced transmission. This confirms observations in Karamoja and worldwide which reveal much IK is under threat and in danger of disappearing, the most serious threat posed to its survival is cultural change (Somnasang \&Moreno-Black, 2000; Srithi et al., 2009; Schillhorn van Veen, 1997; Voeks \&Leony, 2004).

The adulteration and transmission problems indicated so far also reveal the larger problem of modernity's confrontation with local culture. The arrival of modernisation 
and the western world view displace local culture producing a generation's long period of cultural limbo. Cultural limbo, or acculturation, is when persons are unable to identify themselves as fully Karamojong. They become divorced (or at least distanced) from their past, yet are not part of another, more modern culture, a liminal state suffused with uncertainty.

Indigenous knowledge equips people with appropriate coping tools and a framework to enable them in endogenous ways as they (and subsequent generations) stretch between modern and traditional culture, beliefs and norms. As they struggle to reformulate and blend their cultural norms and habits, their morals, attitudes and confidence, they lose much of their traditional culture. Yet, dynamic indigenous coping mechanisms could help guide Karamoja and other traditional societies bridge the gap of this crosscultural transition so that the inevitable approach of modernity does not destroy the local cultural pillars and fracture their cultural identity. The latter fractures when people experience cultural limbo. Given this model, stabilizing traditional indigenous knowledge systems, such as traditional veterinary knowledge, will help not only to improve healthcare but also provide the additional benefit of strengthening cultural identity. Traditional veterinary knowledge or ethnoveterinary knowledge (EVK) is a subset of indigenous knowledge (see Martin et al, 200I; McCorkle, 1986); it covers everything traditionally known and done to keep animals healthy and productive or 'happy' (Mathias \& McCorkle, 2004). By far the most-studied element of EVK has been that of medicinal plants. Unfortunately, there is a danger that this knowledge will soon be lost due to decreased transmission and adulteration with mixtures of other knowledge systems.

\section{Traditional Livestock Healers' Associations (THLA)}

In order to prevent ethnoveterinary knowledge from fading and, as a by-product, use their EVK to strengthen Karamoja's cultural identity, Karamoja Christian Ethnoveterinary Program (KACHEP), a local NGO has helped facilitate the formation of two traditional livestock healers' associations. These associations serve to increase the transmission of knowledge through an additional, new outlet as well as prevent the dilution of IK through adulteration. This provides for the basic healthcare needs for the Karamojong and their livestock. These associations, Pian and Bokora Traditional Livestock Healers' Association (PTLHA and BTLHA), respectively, registered at the national level, are endogenous EVK networks and are important for this current research. Their objective is to preserve, promote and protect Karamoja's EVK: they document and encourage EVK use through various pathways (Gradé et al, 2008). Documentation and transmission here employs farmer to farmer technology dissemination; learning by doing and using, as well as written documentation for dissemination by other local NGOs and their community animal health workers (Gradé et al, 2008).

Pian TLHA's healers gather as a group in rotating communities in and around $\mathrm{Na-}$ bilatuk and Lolachat; whereas as the Bokora healers meet in their own communities in neighbouring Moroto district (see Figure I for TLHA locations). Annually, these two networks, Bokora and Pian TLHAs, come together for a week long joint healers' workshop, 
in either Bokora or Pian. If tension between the clans is running high, then a neutral venue are selected. Even so, some participants fear to travel to any joint healers' workshop due to ongoing hostilities between clans. Typically, nearby community members join and participate in both the local and joint TLHA workshops. Following the one to five day workshop, traditional healers disseminate or drive information back to their own neighbours in their home area (i.e. their circle or horizontal diffusion, as discussed above). These associations form the basis of new means to diffuse EVK and thus increase the number of social (horizontal) contacts for knowledge transmission. They also contribute to vertical knowledge transmission, since youths gather at TLHA workshops to listen and watch. It has been shown that increased social contacts will increase the diffusion of innovations (Rogers, 1995).

Study aim and objectives

In order to investigate if the healers' associations have the potential to prevent ethnoveterinary knowledge from fading, we estimated EVK diffusion of healer-driven networks. We followed the 'knowledge and attitude' methodology of Somnasang and Moreno-Black (2000) and measured EVK of livestock disease and remedies in three different communities in Karamoja.

The aim of this study was to compare EVK knowledge in three study sites to investigate whether and to what extent the organised TLHA-driven EVK has been diffused in Karamoja. This will show whether EVK is being used in community groups, and support the working hypothesis that if the oral history and veterinary knowledge is written down, validated and used in community groups, it will not disappear. We attempted to determine healer-driven (or stimulated) EVK diffusion by surveying people and comparing their EVK in two types of areas: those where registered healers live and/or visit and those where they do not live. Only in the first type of area has EVK been written down, used and validated hand-in-hand with TLHAs. There is virtually no direct exchange between these areas due to distance and distrust. Transmission of EVK takes place between family members and friends. However, the healer associations' format increases transmission between related communities and healers; increased social contacts should increase diffusion. We want to determine if these new transmissions move out beyond the healers' circles. 


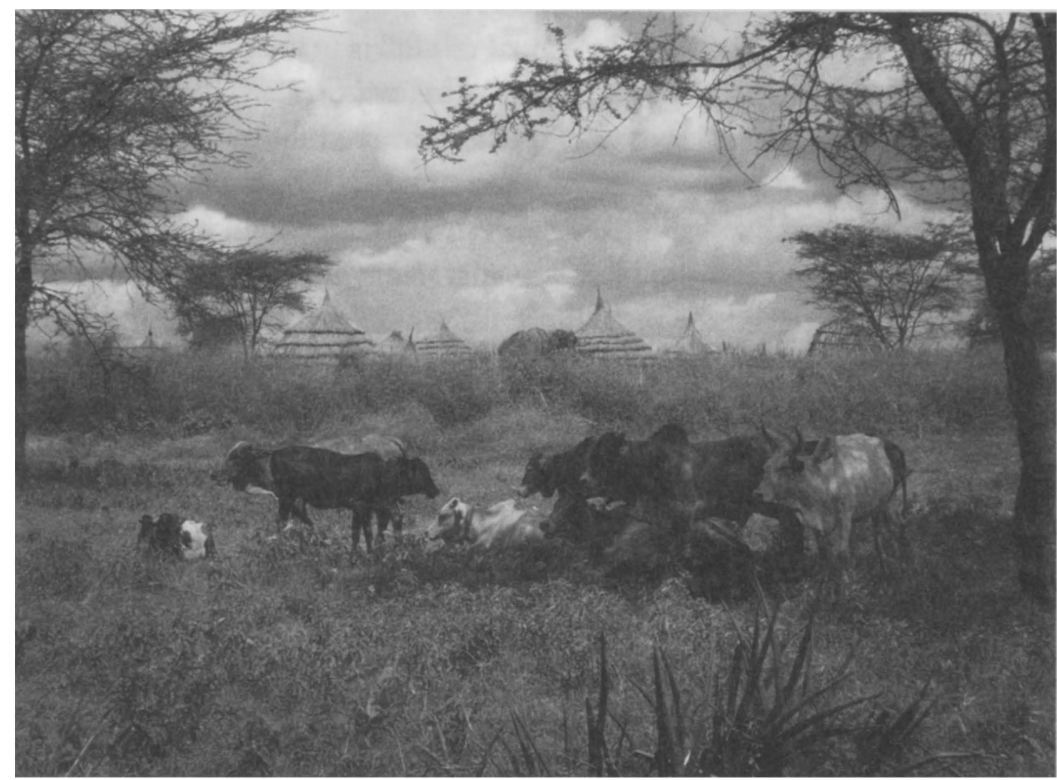

One of the interview points near a Nabilatuk manyatta (settlement), study site A.

This study has one general objective and four specific objectives. The aim is to investigate whether EVK diffusion through traditional healer circles is effective. This is specifically done by measuring ethnoveterinary knowledge, attitude and use scores of selected livestock diseases and traditional remedies to treat both human and animals. The specific objectives are: (I) to compare study site scores in order to ascertain if healerdriven EVK has been diffused; (2) to differentiate between the remedy scores for animal use and the scores for human use; (3) to differentiate knowledge scores between the I4 native remedies and the two introduced plant remedies; and then finally within the introduced plant remedy subset (4) to document any knowledge differences between exotic medicinal plants based on when they were introduced, i.e. the recently introduced Moringa oleifera Lam. (Moringaceae) and the well-established and domesticated, but not native, Azadirachta indica A. Juss. (Meliaceae).

\section{Materials and Methods}

Study site

The Karamoja region covers an area of $28,000 \mathrm{~km} 2$ and is located in northeastern Uganda between $\mathrm{I}^{\circ} 30^{\prime}$ to $4^{\circ} \mathrm{N}$ and $33^{\circ} 30^{\prime}$ to $35^{\circ} \mathrm{E}$. The present study was conducted around three target areas: study site A - Nabilatuk, $2^{\circ} 03^{\prime} \mathrm{N}$ by $34^{\circ} 33^{\prime} \mathrm{E}$; site B - Lorengedwat, $2^{\circ} 23^{\prime} \mathrm{N}$ by $34^{\circ} 35^{\prime} \mathrm{E}$; and site $\mathrm{C}-\mathrm{Kaabong}, 3^{\circ} 30^{\prime} \mathrm{N}$ by $34^{\circ} \mathrm{O} 9^{\prime} \mathrm{E}$ (Figure I). They are found within Karamoja's southern and northern most districts; Nakapiripirit (A and B) and Kaabong (C) districts, respectively. These areas fall within the Karamoja Region climatic zone characterized by a semi-arid to arid agroecological environment with an intense hot 
and dry season (November to March) (Inangolet et al., 2008). There is a single rainy season, with peaks in May and July. Average annual rainfall is in the range of $100 \mathrm{~mm}$ to 625 $\mathrm{mm}$, depending on the year and location (Kamanyire, 2000). Daily temperatures average $30-35^{\circ} \mathrm{C}$. Vegetation is a flat grassland with a few scattered thorn bushes and trees, except along the seasonal rivers, where thickets and sporadic forests occur. The plains, that average $1400 \mathrm{~m}$ in elevation and slope to the west, are punctuated by a triangle of three extinct $>3000 \mathrm{~m}$ volcanoes each about $100 \mathrm{~km}$ apart from another (Gradé et al., 2009b).

Thomas (1943) described the vegetation of Karamoja as consisting of associations of Acacia-Combretum-Terminalia woodland species, with a grass layer of Hyparrhenia, Setaria, Themeda, Chrysopogon and Sporobolus species.

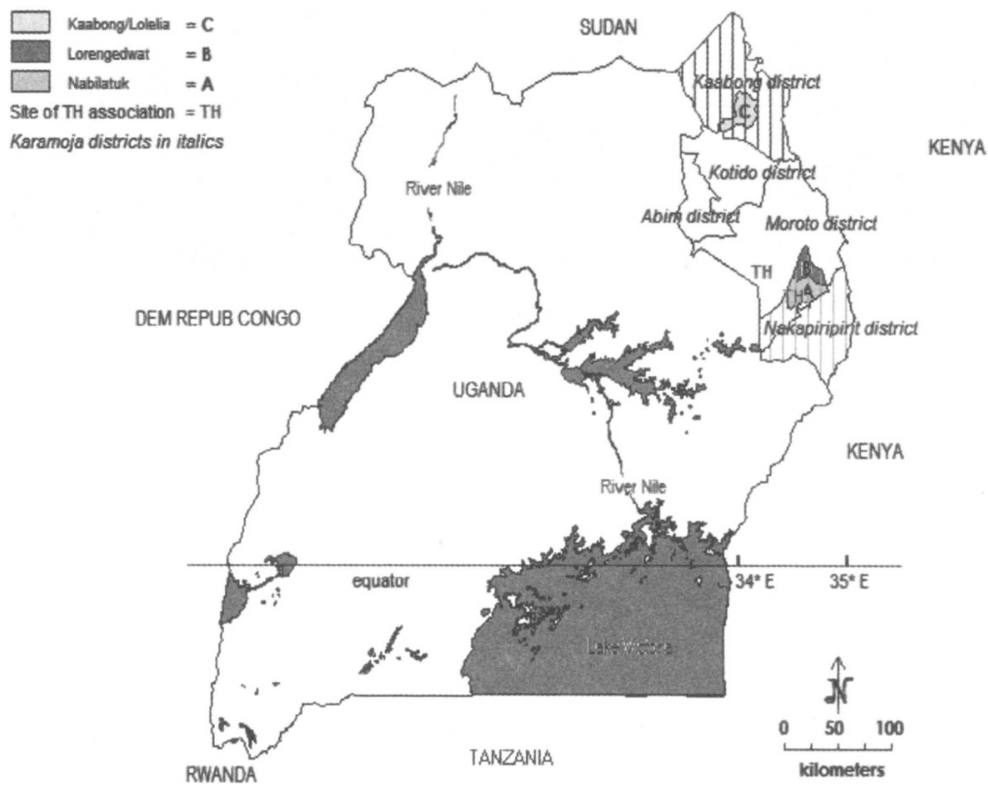

Map of study sites in Karamoja region, Uganda; showing Nakapiripirit district, Pian county, Nabilatuk and Lorengedwat sub-counties (A and B sites, respectively), and Kaabong district, Dodoth county, Kaabong Rural subcounty (site C). Sites of traditional livestock healers' associations are marked by TH in red, one in Pian county (Nabilatuk and Lolachat) and the other in Bokora county, Moroto district. Map designed by primary author using DIVA.

Karamoja consists of five administrative districts which are further divided into counties, sub-counties, parishes and finally smaller units called Local Council One (LCI) areas, composed of villages, locally named "manyattas" or NGIERE. Counties are commonly named after the dominant ethnic group among the inhabitants. The first two sites are found in Pian county; A is found in Nabilatuk sub-county, specifically Kosike parish ( 3 manyattas) and Moru-angibuin parish (one manyatta), whereas B is found in Lorengedwat sub-county, specifically Nasinyonoit parish (3 manyattas) and Kamaturu parish (2 
manyattas). Site $\mathrm{C}$ is in the newly-formed Dodoth county, Kaabong rural sub-county and covers six parishes.

The total population of Karamoja is around 935,000 (Uganda Bureau of Statistics, 2002) consisting of five distinct Nilotic peoples in the plains and two small Kuliak groups found in the mountains (Gulliver, 1952). Karamojong is used as a generic term for the dominant plains people of Karamoja, i.e. Dodoth, Jie, and Karimojong. The Karimojong are further divided into Pian, Matheniko and Bokora ethnic groups. Each of the people group names have a meaning: Dodoth refers to 'cattle colostrum', Jie means 'fighters', whereas Karimojong means 'elders', and refers to the story that while moving in pursuit of settlement land, the elders got tired and remained behind and some even died there, while the more youthful and energetic moved on. People living at sites A and B are from the Karimojong people group, more specifically Pian (after which their county is named); people at site C are Dodoth. Collectively, the Karamojong have less than Io\% literacy, share a transhumant pastoral lifestyle and a number of rituals, but they rarely collaborate peaceably with other clans due to tribal warfare (Gradé, et al., 2008a).

Site A, Nabilatuk is the base study site, from which we tested our hypothesis. All Pian TLHA members live within Nabilatuk or Lolachat, whereas the Bokora TLHA members live in the next district (see Figure I, TH symbol); none live in study sites B and $C$. Registered healers regularly meet with one another both by happenstance and on organised occasions for participatory EVK sharing and subsequently share these topics with their family and fellow community members (see TLHA section). Those participants interviewed in A had a high level of opportunity to interact with THs and/or their families prior to the study period. The second site, Lorengedwat (B) is a community where those interviewed may have interacted with Nabilatuk community members and were less likely to have engaged with the registered Bokora healers' circle. However, moderate distance and poor relations greatly minimise any of these possible interactions. The third community, Kaabong (C) consists of people who, due to distance, but also the risk of small-arms conflict between neighbouring clans throughout the region, have had virtually no chance to interact with members of the other two communities or either of the healers' circles.

\section{Study site similarities}

All study sites are within a moderate walking distance from a small town, Nabilatuk, Lorengedwat and Kaabong, respectively. However, site $\mathrm{C}$ is the most distant from a large town, and is therefore considered the most remote from civilisation. As stated in the introduction, the more remote a community, the more dependent they are on indigenous knowledge. None of the sites chosen are in direct conflict with one another. However, they do not interact as their territories and the buffer zones between them are composed of wide uninhabited areas with rare transport opportunities and often unstable security.

The three study sites are similar in that they have minimal access to conventional western medicine compared to the rest of Uganda. In terms of primary human health care, Kaabong has a small hospital, Nabilatuk has a health centre and Lorengedwat has a simple clinic connected to the Catholic Church. All these health posts, however, have 
chronic staff, equipment and medicine shortages. Two NGOs are involved in animal health care. They provide information on western medicines and use it for treatments. One of the NGOs is present both in Nabilatuk and Lorengedwat, whereas the other is stationed in both Nabilatuk and Kaabong. In 2006, a district veterinary officer (DVO) was assigned to Kaabong town, the district headquarters. Apart from this recent change which occurred 6 months before the survey, each study site is more than two hours away from their respective DVO.

The agro-ecology is similar over the three sites with some small differences. For example, rains and subsequent growing season at site $\mathrm{C}$ lag two months behind those of the other two sites. However, all plants and diseases that we asked about were commonly found near all three sites.

\section{Data collection methods}

From May to June 2007, we interviewed a total of 180 people, 60 per site, a representative sample based on age, location and gender. Some people interviewed are considered healers, although they were not at the time registered members of the said associations. All participants, save a few students, are pastoralists.

We used a pre-tested knowledge, attitude and practices (KAP) survey (Somnasang \& Moreno-Black, 2000) with two sets of questionnaires, remedies and diseases; consisting of I6 remedies and 12 different livestock diseases, respectively. These were randomly selected from a long list of remedies and diseases that healers had actively shared at their regular association meetings from I999-2004 (KACHEP project report, 2005). The 16 remedies included $\mathrm{I}_{3}$ indigenous plants, one local mineral and two introduced plant species. All of the 12 livestock ailments are common throughout Karamoja. Four traditional healers from both the Pian and Bokora associations served to pre-test the KAP survey in order to improve and make any adjustments to the question sets, as well as to develop an answer sheet for scoring KAP. The answer sheet was later used to compare the respondents' answers and score their knowledge, aptitude and practice. Those selected for the pre-test were not re-interviewed. Thirty people were then randomly selected from each study site (A, B and C) for each of the two question sets (i.e. 6o total participants for each site), and there were $\mathrm{I}$ to 3 extra informants in case of any data errors.

A total of four people acted as interviewers. The primary author, Jeanne Gradé, performed the first five interviews while the other three interviewers and four assistant-interviewers observed. After this training, interview teams went out by twos: one to interview (in Ngakarimojong) and write in English, and an assistant to write answers in the vernacular language. Assistants were selected from people living in each study area who were able to write and understand the local dialect and were held in respect by the community. These were either the LCI leader, extension workers or traditional healers. One of the interviewers, a foreign student, asked questions in English whereas her assistant translated. All other interviews, therefore, were primarily conducted in Ngakarimojong and followed structured questionnaire format to decrease variability. Answers were written in both languages (English and the vernacular) so that the primary author could thorough- 
ly analyse the answers. Interview transcriptions were scored according to a pre-defined answer sheet. They were arranged according to a range of information: informant answers, pre-test KAP surveys, key healers' feedback, TLHAs' partner NGO (KACHEP) lesson plans and with guidance from Makerere University's Botany and Statistics departments in Kampala. The answer sheet is related to knowledge; it contains the facts or the right answers that had to be given and the responses are compared to this answer sheet to obtain a knowledge score. Thus, the answer sheet shaped a scoring format to tabulate narrative answers into a raw score. Scores were as follows: 0 if a respondent did not answer according to the answer sheet (no knowledge), I if their answers were partially correct (some knowledge) and 2 if their answers completely matched the answer sheet or went beyond (high knowledge). For statistical analyses, binomial variables ('no knowledge' and 'knowledge') were used, thus scores of $\mathrm{I}$ and 2 were converted to $\mathrm{I}$ to represent knowledge (see analysis section and Somnasang \& Moreno-Black, 2000).

The KAP survey was divided into two segments, remedies and diseases, of which participants took only one segment. Each segment had four sections and 9 questions. The four sections were: identification, knowledge of use/treatment, recent personal use, and personal confidence. The first KAP survey question was identification. For identification of remedies, laminated photographs (Picture 2) were shown for each of the 15 plants following Thomas et al. (2007), whereas for the $16^{\text {th }}$, a local mineral, a real sample was shown (Somnasang \& Moreno-Black, 2000). Informants were able to handle all materials while deliberating their answer. If they correctly identified it within a short time, their score was 2. If they took more time or if they initially guessed incorrectly, but eventually answered correctly, they received one point. The same scores were assigned if they used a synonymous, but correct, name for a remedy. This was especially relevant for study cite $\mathrm{C}$, as the Dodoth language is slightly different from that of Pian. If correspondents did not correctly identify the remedy (zero score), the interviewer revealed the correct answer so that they could still answer subsequent questions relating to the remedy (see below). For disease identification, informants were told the name of a disease and then asked to describe its symptoms, whereby the same scoring applied. 


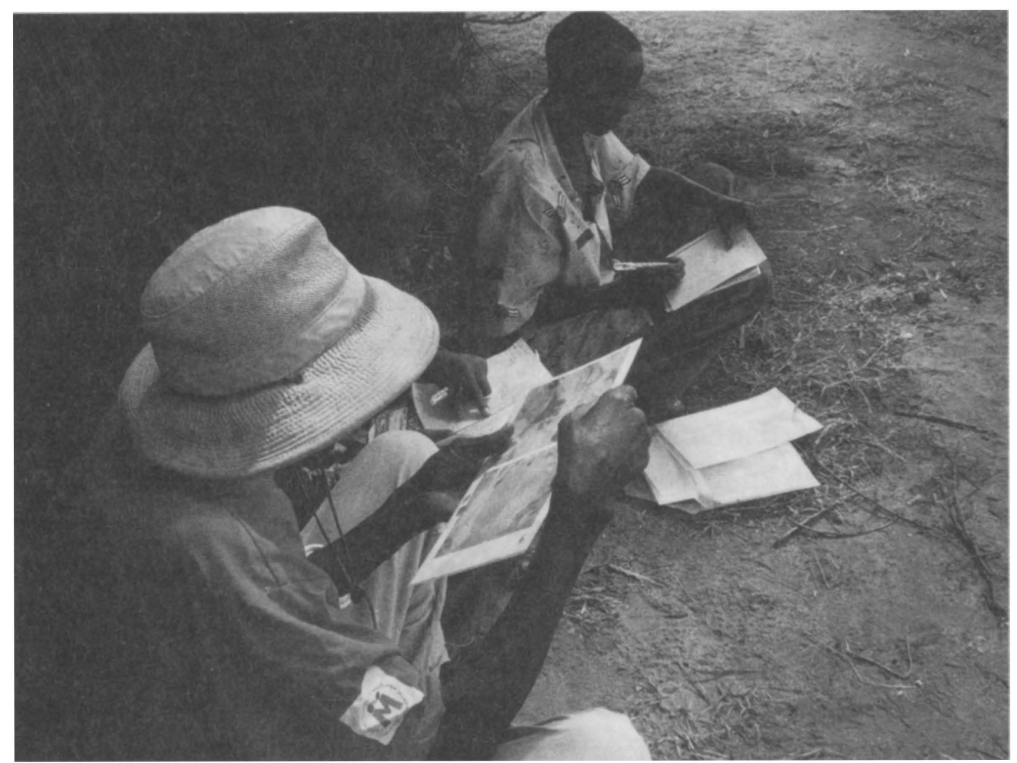

Survey of plant identification with laminated photos in Kaabong.

In addition to remedy identification, the KAP survey measured informants' knowledge of use for both animal and human needs, plant growth habit, availability, conservation and harvesting, and recent active use ( 6 month, >I year or never) and confidence in the particular remedies. Furthermore, the questions relating to disease KAP included: disease symptomology (identification), treatment and prevention; causality; epidemiology, with emphasis on both animal and zoonotic potential; recent active treatment (any treatment); and difficulties encountered when treating livestock with the particular disease. We tabulated overall remedy and disease scores for each individual, respectively, to calculate the informant's 'knowledge scores' according to Somnasang and MorenoBlack (2000). The latter were then summed up within each study site so that knowledge scores could be compared across sites to test the hypothesis that the level of knowledge varies according to the distance from active, registered traditional healers' homes. Some remedies were separated out from the total knowledge scores to distinguish between those plant species that are indigenous versus those that are introduced. We assume that introduced plant species are probably affected by the diffusion of previous training and/ or the effectiveness of those trained to share their knowledge with others, with the further assumption that the next generation of listeners would adopt the knowledge.

\section{Analysis}

We applied a combination of statistical tools to analyse the data. To assess whether knowledge differed between sites, we used generalized linear models (GENMOD) procedure in SAS (SAS Institute, 2003), with score as the response variable and "sites" as the explanatory variable. We used two separate models for "remedies" and for "diseases". 
The variable "site" was entered as a categorical variable with three levels (corresponding to the three study sites) while the score was considered continuous. The score variable was not normally distributed for both models, even after several logarithmic transformations. Since our data had several "zeros" and were all integers, we fitted a Poisson distribution to our models with a log link.

Generalized linear models were also used in order to compare people's knowledge of native ( 12 plant species and one mineral) and introduced species between the three sites. Furthermore, we compared different sites' knowledge levels between the two introduced species, i.e. the recently introduced Moringa oleifera (Picture 3 ) and the well-established and domesticated, but not native, Azadirachta indica.

To compare the knowledge level score for animal use (a measure of "ethno-veterinary knowledge"; EV) to the score for remedy use in humans (a measure of "ethno-medical knowledge"; EM), we generated contingency tables (Tables I and 2) and performed tests of two proportions both between sites and within sites. To test proportion, we utilised Pearson's chi-square test and, when the expected counts of cells $<5$, then Fisher's exact test was applied. Fisher's is a statistical significance test used in the analysis of categorical data where sample sizes are small, whereas chi-square is used if $\mathrm{n}$ is large. Additionally, Fisher's was used because the data were slightly unbalanced (Agrestia, 1996). All analyses were performed in SAS with the level of significance set at $5 \%$.

\section{Results}

Knowledge diffusion based on total scores

We found that knowledge evidenced by the total score varied significantly between study sites for both "diseases" and "remedies" as their total scores were significantly higher in at least one of the sites (see Figure 2). For disease, the score was higher in site A than in both site $B\left(x^{2}=3.81, d f=I, P=0.05\right)$ and site $C\left(x^{2}=58.07, d f=I, P<0.001\right)$, and higher in site $B$ than in site $C\left(x^{2}=32.20, d f=I, P<0.00 I\right)$. Similar results were obtained for remedies, i.e. the score was higher in site $A$ than in both site $B\left(x^{2}=31.67, d f=I\right.$, $\mathrm{P}<0.001)$ and site $\mathrm{C}\left(\mathrm{x}^{2}=95 . \mathrm{I} 9, \mathrm{df}=\mathrm{I}, \mathrm{P}<0.00 \mathrm{I}\right)$, and higher in site $\mathrm{B}$ than in site $\mathrm{C}\left(\mathrm{x}^{2}=\right.$ $\mathrm{I} 6.52, \mathrm{df}=\mathrm{I}, \mathrm{P}<0.00 \mathrm{I})$. So for both "diseases" and "remedies", total score site A > total score in site $\mathrm{B}>$ total score in site $\mathrm{C}$ (Figure 2). 


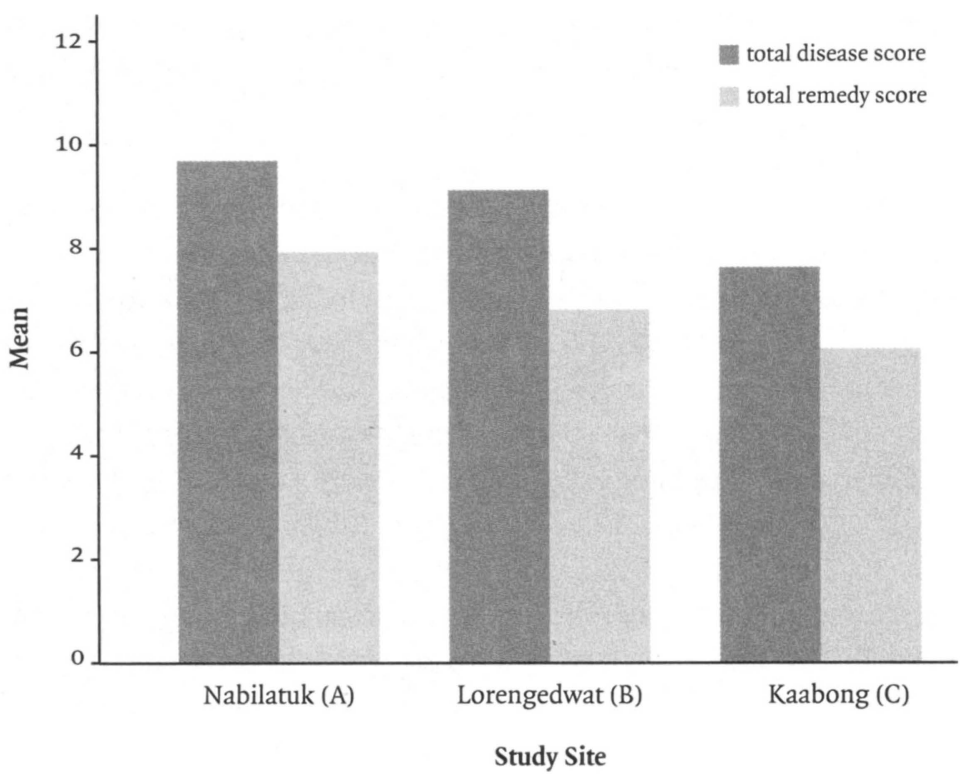

Figure 2: Pastoralists' indigenous knowledge levels (mean $\pm \mathrm{SE}$ ) in relation to their total disease score (dark bar) and total remedy score (open bar) for different study sites. Means are reported on a normal scale for illustration purpose (analyses were performed on log scale).

Remedies' ethnoveterinary use versus ethnomedicine use

Tables $\mathrm{I}$ and 2 display the mean knowledge scores of the same remedies for use in either livestock (EV, Table $\mathrm{I}$ ) or people (EM, Table 2). The data is pooled into binomial variables ("no knowledge" vs. "knowledge"), allowing us to compare the proportion using the test of two binomial proportions between sites, but also EV vs. EM within a site. We found that knowledge scores for remedies' uses in livestock also varied with site: EV score was higher in site A than in both site B (Fisher's exact test; $z=-6.15, P<0.001$ ) and site $C(z=-16.10, P<0.001)$, and higher in site $B$ than in site $C(z=-9.28, P<0.001)$. EM was higher in site $A$ than in site $C(z=-5.7, P<0.001$, and in site $B$ than in site $C(z=-5.52$, $P<0.00 I)$, but was not different between sites $A$ and $B(z=-0 . I, P=0.9)$. Overall, $E V$ in site $A>E V$ in site $B>E V$ in site $C$, while the pattern was somewhat different for EM (EM in site $\mathrm{A}=\mathrm{EM}$ in $\mathrm{B}>\mathrm{EM}$ in site $\mathrm{C}$ ). 


\begin{tabular}{cccc}
\hline study site & no knowledge & knowledge & Total $\mathbf{n}$ \\
\hline A & $42(8.2 \%)$ & $465(91.8 \%)$ & 507 \\
\hline B & I06 (22.2\%) & $372(77.8 \%)$ & 478 \\
\hline C & $245(49.5 \%)$ & $250(50.5 \%)$ & 495 \\
\hline
\end{tabular}

Table 1: Respondents' knowledge (proportion in brackets) on remedies use in animals in the three study sites, $n$ is the total number of respondents' answers per site.

\begin{tabular}{cccc}
\hline study site & no knowledge & knowledge & Total $\mathbf{n}$ \\
\hline A & I29 (25\%) & $378(75 \%)$ & 507 \\
\hline B & I23 $(25.7 \%)$ & $355(74.3 \%)$ & 478 \\
\hline C & $209(42.2 \%)$ & $286(57.8 \%)$ & 495 \\
\hline
\end{tabular}

Table 2: Respondents' knowledge (proportion in brackets) on remedies use for people in the three study sites, $n$ is the total number of respondents' answers per site.

We also compared both EV and EM scores within study sites. We found EV score to be higher than EM score for site A (Fisher's exact test; $z=-7.5, P<0.001$ ), EV score was lower for site $C$ than $E M$ score $(z=2.3, P=0.02 I)$, whereas there was no difference between both scores for site $B(z=-1.29, P=0.19)$. Our results show that the likelihood that people in site A would have > no knowledge of $\mathrm{EV}$ is $8 \%$ as compared to for $\mathrm{EM}$. That means, responding with a wrong answer to a question testing knowledge is $17 \%$ higher for $\mathrm{EM}$ compared to EV. This indicates less knowledge on EM than on EV, this also holds true for site $\mathrm{B}$. Interestingly, people in study site $\mathrm{C}$ have more knowledge ( $7 \%$ ) on EM than EV. These correspondents, however, have less overall EV and EM in comparison with both other study sites.

In summary, site A had far greater knowledge on remedies' use in animals than for the same plants' use in people. Likewise, site B had more EV than EM but not as marked as site $\mathrm{A}$. However, site $\mathrm{C}$ informants scored higher on people's use than livestock useknowledge for the same remedies. Thus, we have the pattern: A - EV>>EM, B - EV >EM and $\mathrm{C}-\mathrm{EV}<\mathrm{EM}$.

Knowledge scores of indigenous versus introduced plant species

We compared knowledge scores within each study site for exotic plants vs. the indigenous plant treatments, and found there were no differences (all $\mathrm{P}>0.05$ ). However exotic plant knowledge scores, as well as indigenous plant knowledge, varied significantly between study sites. Indeed, the exotic species score was much higher in site A than in site $C\left(x^{2}=95.5 I, d f=I, P<0.00 I\right)$ and also higher than in site $B\left(x^{2}=0.146, d f=I, P<0.00 I\right)$. Similarly, site $B$ scored higher than site $C\left(x^{2}=0.134, d f=I, P<0.001\right)$, thus the score in site $A>$ the score in site $\mathrm{B}>$ the score in site $\mathrm{C}$ for knowledge about exotic plant species use. 
On the other hand, the indigenous remedy scores were significantly higher for site A than for both site $B\left(x^{2}=4.47, d f=I, P=0.035\right)$ and site $C\left(x^{2}=5.60, d f=I, P=0.018\right)$, whereas there was no significant difference between site $B$ and site $C(P>0.05)$. This produces the pattern the score in site $\mathrm{A}>$ the score for site $\mathrm{B}=$ the score for site $\mathrm{C}$.

Long term introduced plant versus recently introduced plant knowledge

Results showed that distance (a measure of the difference between sites), specifically from the registered healers association base, had no effect on the well-established and domesticated Azadirachta indica ( $P>0.05)$. Thus, knowledge score in site $\mathrm{A}=\mathrm{score}$ in site $B=$ score in site $C$. However, distance did have an affect upon knowledge scores of the more recently introduced Moringa oleifera $(\mathrm{P}<0.001)$. Study site A had significantly more knowledge than both sites $B\left(x^{2}=9.98, d f=I, P=0.002\right)$ and $C\left(x^{2}=4.52, d f=I, P=0.033\right)$. There were no significant differences between study site B and C's knowledge levels for Moringa oleifera $(\mathrm{P}>0.05)$. Again, we observe the pattern for knowledge scores in site $\mathrm{A}>$ score in site $\mathrm{B}=$ score in site $\mathrm{C}$.

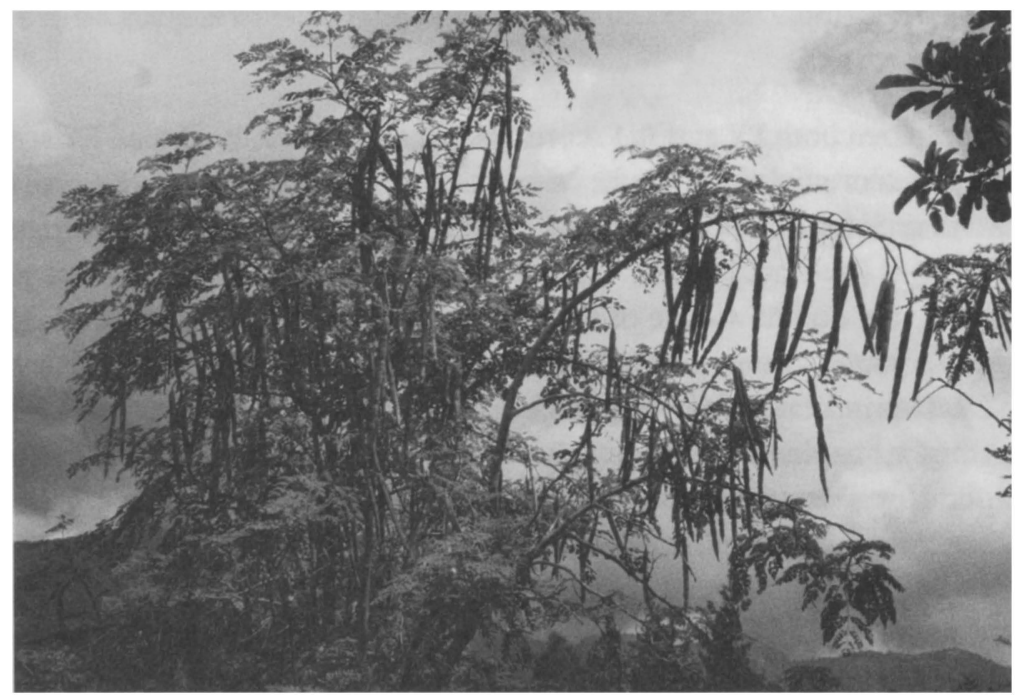

Moringa thriving in Karamoja as an introduced plant species.

\section{Discussion}

We found a significant difference in ethnoveterinary knowledge between study sites. Scoring results to measure ethnoveterinary knowledge, attitude and use of the $180 \mathrm{Ka}$ ramojong interviewed on livestock disease and remedies, show that the distance from the Pian healers' association significantly influenced the overall EVK score. Indeed, we found that EVK was higher in Nabilatuk than in the other locations, while Lorengedwat scored better than Kaabong. Distance from the Pian healers' association is significantly correlated to knowledge about livestock disease and remedies. 
Results show that study site A, near Nabilatuk, base of the Pian TLHA, had significantly higher scores for each query on the remedy questionnaire set. This means that this site's correspondents had more knowledge related to certain aspects of the selected remedies, including: remedies' identification; knowledge of use (for both animal and human needs); plants' growth habits, availability, conservation status and appropriate harvesting technique; and recent actual use of the remedies questioned, as well as a selfassessment of their confidence in using the remedy in question.

Furthermore, informants from site A, on the whole, consistently scored higher on each question in the disease questionnaire. This aptitude was evidenced in disease symptomology, treatment and prevention; causality; epidemiology; and zoonotic potential knowledge. They also appear to have treated these diseases more recently and therefore seem more confident and experienced in terms of treatment than those in the other areas. Additionally, their confidence self-assessment was higher (as part of the scores in Figure 2).

This corroborates Vandebroek et al.'s (2004b) hypothesis that social variables underlying indigenous medical practices are important in determining medicinal plant knowledge and transmission, even more so than the remoteness or isolation and/or level of plant biodiversity of the studied communities. Specifically, the social variables are the healing traditions of the extended family and the presence of healers' networks. In Bolivia, Andes communities with a semi formal healers' network (AMETRAC) tested higher on knowledge than a more floristically-rich and remote Amazonian community that did not have a healers' network (Vandebroek et al., 2004a). Although not more floristically rich, Kaabong is the most remote site studied here, yet does not have a formal healers' association, whereas Nabilatuk (A) does.

Communities located close to active, registered TH manyattas have a higher level of knowledge related to exotic plant remedies than areas distant from their homes. This is supported by the observation that site A scored higher than sites B and/or C (Figure 2). Interestingly, ethnomedical (EM) remedy use scores do not significantly differ between sites A and B. Additionally, site C, while having lower scores than A and B, had basically the same level of knowledge on EV as on EM (Tables I and 2, 0.495 and 0.422 ), and actually had higher scores in EM than EV.

Treatment of human diseases was not the focus of the organised TH workshops. Thus, the introduced means of diffusion - the traditional healers' fora and relationships - were not stimulated to promote EM. We can use ethnomedicine knowledge scores as a baseline control of EV. If we assume that before the Pian and Bokora healer associations were organised, the knowledge levels for local medicines of both EV and EM within sites ( $A, B$ and $C$ ) were roughly the same, we would expect EV (and overall EVK score) would increase initially at A (due to THs sharing) and then that knowledge would diffuse to $B$ and then eventually to $C$. We could also assume that, since TLHAs primarily share information about livestock care, as opposed to human health, EM would not dramatically increase in A and subsequently B. We could further assume, since they have only been meeting in an organised fashion for six years, their EVK diffusion has not yet reached site $\mathrm{C}$ so we would expect that their EM and EV would be unchanged from the baseline date 
and that EM and EV would basically be even (same scores). Based on these findings, we can make a preliminary conclusion in favour of these assumptions contingent on future empirical findings. Namely, that the healers of Nabilatuk have shared their EVK effectively and actively encouraged its diffusion.

We have also looked at the knowledge level differences between native and introduced plant remedies. In this case, there is no difference within any of the sites. However, comparing site with site, there are differences in both types of remedies, with A (still) being the most knowledgeable. At the level of introduced remedy knowledge, A had much more knowledge than $\mathrm{C}$ whereas the knowledge level was to a certain extent also higher than that for B. For indigenous plant knowledge level, B and C were the same, although both were less than A. Similarly, when we examine knowledge levels with respect to the relatively recently introduced Moringa, there was no difference between $B$ and $C$, although both scored less than A. Interestingly, there were no differences in score levels between the three sites for the well-established and naturalised Neem tree (Azadirachta indica). These results could mean that TLHAs have been effective in teaching livestock practices to their peers and neighbours, but that this knowledge has not yet effectively diffused out to B and C. It appears that since Neem has been a long-time feature, and has been promoted through missions and NGOs, that pastoralists throughout the study sites have high and even knowledge levels on its uses as evidenced by scores that most use neem. We assume that, 50 years ago, when Neem was first introduced to the area, planted at Christian missions and around Muslim mosques, and later in Karamoja's only major towns (Moroto and Kotido), Neem knowledge levels would have initially been extremely low. Ranging from the missions to district headquarters, where today we can see wellestablished trees, Neem has thrived in Karamoja's dry environment. However, because it must be planted, watered and cared for (except for saplings under well-established mother trees), it is extremely rare to see this tree in more remote manyattas. Interestingly, however, we did see a number of young Neem trees growing at a few manyattas in and near study site A - the work of TLHA hands (KACHEP report, 2004).

Total knowledge score clearly shows that KAP levels are higher in site A than B $(A>B)$. This indicates that registered traditional healers, through their workshops and personal contacts, have been effective at information dissemination about local diseases and remedies and this knowledge has later diffused to $\mathrm{B}$. This hypothesis is confirmed (or strengthened) in that C's knowledge score was much lower. Community members from $A$ and $B$ may interact with one another but these opportunities are still somewhat limited. The most common face-to-face scenarios are at the kraals (migratory cattle camps) and some rare market interactions. Much of the diffusion probably occurs through close interpersonal contacts which have been and continue to be the means by which news filters through communities in this predominantly oral culture. 


\section{Conclusions}

Partnerships such as those with local NGOs and TLHAs, in documenting and disseminating Karamojong EVK, introduce additional means to help keep EVK alive and to help spread it further. Furthermore, facilitating and encouraging regular TLHA meetings adds value to an endogenous way to stimulate EVK promotion. Community members from $\mathrm{C}$ and $\mathrm{A}$ will, from tradition, not interact in the current socio-cultural framework. Indeed, they probably will not interact until a few generations after 'development covers Karamoja' and brings peace to the area, but there is a danger that this EVK will be lost. If they no longer actively use EVK, it will fall into disuse, or become adulterated with mixtures of other knowledge systems. Currently, if A and C community members interact, it is outside of the indigenous pastoral Karamojong culture and therefore, extremely rare. It would be, for example, politicians or school boys - who most probably have already shunned their ancestral knowledge or culture for 'modernwestern' ways and therefore would not be the channels of EVK dissemination.

If the transmission avenues work, then information should not only pass through them, but technology adoption should also take place. That is, people should be knowledgeable about livestock diseases and remedies and actively using the knowledge that has been shared in different areas. Because community B had a higher level of livestock diseases and remedies than community $\mathrm{C}$, we can assume that facilitating the formation of livestock healers' associations can add more ways for indigenous knowledge dissemination. It is partly through this avenue that information passed from $A$ to $B$, and eventually could carry on to $C$. Furthermore, the endogenous pipeline of TLHAs and local NGOs could help to carry EVK, together with the recently available written documentation.

In conclusion, all the results presented here indicate that the healers of Nabilatuk have shared their ethnoveterinary knowledge effectively and encouraged its diffusion in the studied areas. These results support the working hypothesis that knowledge will not disappear if it is used and communicated (orally, practically and written) through all available networks, both endogenous and exogenous. This may help spare the Karamojong pastoralists from a future stage of 'cultural limbo', which many traditional cultures elsewhere have experienced as modernity disrupts both people and land. It will thus enable a smoother transition into the next cultural identity era in which Karamoja reaches a sustainable independent way of living in conjunction to with the modern context. Written EVK documentation should be locally available to be used appropriately in schools, and by TLHA, NGO and GO networks.

\section{References}

Agresti, A. (1996) An introduction to categorical data analysis. New York: John Willey \& Sons.

Dyson-Hudson, R., Meekers, D., \& Dyson-Hudson, N. (1998). Children of the dancing ground, children of the house: Costs and benefits of marriage rules (South Turkana, Kenya). Journal of Anthropological Research, 54(I): 19-47.

Gomez-Beloz, A. (2002). Plant use knowledge of the Winikina Waroa: the case for questionnaires in ethnobotany. Economic Botany, 56(3): 231-24I.

Gradé, J., Tabuti, J., \& Van Damme, P. (2009a). Four footed pharmacists: indications of self-medicating livestock in Karamoja, Uganda. Economic Botany, 63(I): 29-42. 
- (2009b). Ethnoveterinary knowledge in pastoral Karamoja, Uganda. Journal of Ethnopharmacology, I22(2): 273-93.

(2008). Building institutions for endogenous development: using local knowledge as a bridge. In: P. Sanginga, A. Waters-Bayer, S. Kaaria, N. J. \& C. Wettasinha (Eds.), Innovation Africa: Enriching Farmers' Livelihoods, pp. 255-266. London: EarthScan.

Gradé, J., Tabuti, J. R. S., Van Damme, P., \& Arble, B. L. (2007). Deworming efficacy of Albizia anthelmintica in Uganda: preliminary findings. African Journal of Ecology, 45(s3): 18-20.

Gulliver, P. H. (1952). The Karamajong Cluster. Africa: Journal of the International African Institute, 22(I): I-22.

Kamanyire, M. (2000). Natural resource management and policy in Uganda: overview paper: the effects of policy and institutional environment on natural resource management and investment by farmers and rural households in east and southern Africa. Manchester: Institute for Development Policy and Management, University of Manchester.

KACHEP (2004) Internal semi-annual progress report (unpublished) accessed at their coordinating office.

- (2005) internal semi-annual progress report (unpublished) accessed at their coordinating office.

Ladio, A., \& Lozada, M. (2001). Nontimber forest product use in two human populations from Northwest Patagonia: a quantitative approach. Human Ecology, 29(4): 367-380.

Mandani, M. (1986). The colonial roots of the famine in Karamoja: a rejoinder. Review of African Political Economy, 13(36): 85-92.

Martin M., Mathias E. \& McCorkle C. M. (200I). Ethnoveterinary medicine: an annotated bibliography of community animal healthcare. London: ITDG Publishing.

McCorkle C. M. (1986). An introduction to ethnoveterinary research and development. Journal of Ethnobiology, (6) I: 129149.

Muhereza, F., \& Otim, P. (2002). Pastoral resource competition in Uganda. Case studies into commercial livestock ranching and pastoral institutions. Utrecht: International Book.

Philander, L. E., Makunga, N. P., \& Ellen, R. (2008). Transmission of medicinal plant knowledge in urban Cape Town. South African Journal of Botany, 74(2): 375-375.

Quam, M. D. (1978). Cattle marketing and pastoral conservatism: Karamoja District, Uganda, 1948-1970. African Studies Review, 2I(I): 49-7I.

Rogers, E. M. (1995). Diffusion of Innovations. New York: Free Press.

SAS Institute Inc. (2003). The SAS system for Windows, Release 9.1. Cary: SAS Institute.

Schillhorn van Veen, T. W. (1997). Sense or nonsense? Traditional methods of animal parasitic disease control. Veterinary Parasitology, 71: 177-194.

Somnasang, P., \& Moreno-Black, G. (2000). Knowing, gathering and eating: knowledge and attitudes about wild food in an Isan village in northeastern Thailand. Journal Ethnobiology, 2(20): 197-216.

Srithi, K., Balslev, H., Wangpakapattanawong, P., Srisanga, P., \& Trisonthi, C. (2009). Medicinal plant knowledge and its erosion among the Mien (Yao) in northern Thailand. Journal of Ethnopharmacology, 123 (2): 335-342.

Stangeland, T., Dhillion, S. S. \& Reksten, H. (2008). Recognition and development of traditional medicine in Tanzania. Journal of Ethnopharmacology, $117(2): 290-299$.

Thomas, A. S. (1943). The Vegetation of the Karamoja District, Uganda: an Illustration of biological factors in tropical ecology. The Journal of Ecology, 31(2): 149-177.

Thomas, E., Vandebroek, I., \& Van Damme, P. (2007). What works in the field? A comparison of different interviewing methods in ethnobotany with special reference to the use of photographs. Economic Botany, 6I(4): 376-384.

Uganda Bureau of Statistics (2002). Population Census. Kampala: UBOS. 
Vandebroek, I., Calewaert, J. B., De jonckheere, S., Sanca, S., Semo, L., Van Damme, P., et al. (2004). Use of medicinal plants and pharmaceuticals by indigenous communities in the Bolivian Andes and Amazon. Bulletin of the World Health Organization, 82(4): 243-250.

Vandebroek, I., Van Damme, P., Van Puyvelde, L., Arrazola, S., \& De Kimpe, N. (2004). A comparison of traditional healers' medicinal plant knowledge in the Bolivian Andes and Amazon. Social Science \& Medicine, 59(4): 837-849.

Voeks, R. A. \& Leony, A. (2004). Forgetting the forest: assessing medicinal plant erosion in eastern Brazil. Economic Botany 58: S294-S306.

World Health Organisation (2002). Traditional medicine-growing needs and potential. WHO Policy Perspectives on Medicines, (2): I-6.

\section{Acknowledgements}

I wish to thank the communities of Karamoja, the traditional healers and their associations for sharing with us and promoting Karamoja's ethnoveterinary knowledge whom I've had the delight to work with since the late I990's. Furthermore, we are all indebted to KACHEP for their strong advocacy for Karamoja's pastoralists. 